\title{
Trees Alone Cannot Be the Answer to Climate Change of Present Millennium
}

\author{
Fayaz Ahmad Bhat* \\ Department of Environmental Sciences/Centre of Research for Development (CORD), University of Kashmir (J\&K), India
}

Received: April 04, 2018; Published: April 13, 2018

*Corresponding author: Fayaz Ahmad Bhat, Department of Environmental Sciences/Centre of Research for Development (CORD), University of Kashmir (J\&K), India, Email: fayazevs@gmail.com

\begin{abstract}
Climate change is caused by emission of greenhouse gases (GHGs) through anthropogenic activities including land-use change, deforestation, biomass burning, draining of wetlands, soil cultivation and fossil fuel combustion. Consequently, the concentration of atmospheric greenhouse gases and their radiative forcing have progressively increased with increase in human population, especially from the onset of industrial revolution around 1850. Thus, unless necessary steps are not taken to reduce $\mathrm{CO} 2$ emissions by increasing carbon sinks in terrestrial ecosystem alone, it is not possible to stabilize or reduce concentration of $\mathrm{CO}_{2}$ in the atmosphere.
\end{abstract}

Keywords: Greenhouse; Population growth; Carbon dioxide; Methane; Nitrous oxide

\section{Introduction}

\section{Trendsin Rise in Atmospheric Carbon Dioxide Concentration}

Anthropogenic greenhouse gas emissions have increased since the pre-industrial era, driven largely by industrial and population growth, and are now higher than ever. This has led to atmospheric concentrations of carbon dioxide, methane and nitrous oxide reach to unprecedented levels. Their effects, together with those of other anthropogenic drivers, have been detected throughout the climate system and are extremely likely to have been the dominant cause of the observed warming since the mid-20th century. Changes in many extreme weather and climate events have been observed since about 1950 IPCC [1]. Some of these changes have been linked to human influences, including a decrease in cold temperature extremes, an increase in warm temperature extremes, an increase in sea level and an increase in the number of heavy precipitation events in a number of regions. It has been observed that $\mathrm{CO}_{2}$ emission is on the rise and may continue to rise for many more years due to our dependence on fossil fuels IPCC [2].

\section{Trees Alone Cannot be the Answer to Climate Change}

Accumulation of $\mathrm{CO}_{2}$ in the atmosphere is a dynamic function of the balance between the amount of $\mathrm{CO}_{2}$ emitted by the world and the total amount of $\mathrm{CO}_{2}$ sequestered by the planet (through photosynthesis) during a given period of time.

Atmospheric $\mathrm{CO}_{2}$ concentration $=\mathrm{CO}_{2}$ Emission $-\mathrm{CO}_{2}$ Sequestration ----- Eqn. (1)

From the above equation, it is evident that growing more trees can reduce atmospheric $\mathrm{CO}_{2}$ concentration. Globally, the rate of deforestation is much larger than that of reforestation. Recent studies estimated a net emission of GHGs from the Mato Grosso region of Brazilian Amazon, ranging from 2.8 to $15.9 \mathrm{Gt} \mathrm{CO}_{2}$-eq from 2006 to 2009 [3,4]. It was reported that between 1996 and 2005, the Brazilian Amazon rainforest was deforested by $19,500 \mathrm{~km}^{2}$ per year and converted to pastures and farmland releasing 0.7 to $1.4 \mathrm{Gt}$ $\mathrm{CO}_{2}$ - eq $\mathrm{yr}^{-1}$ to the atmosphere [5]. Avoided deforestation is the best means of Afforestation, new and massive efforts at planting more trees should be a parallel strategy in order to reduce build-up of $\mathrm{CO}_{2}$ in the atmosphere. Many governments around the world, including India have taken up massive tree planting programmes with the slogan that trees are the answer to global warming.

While growing trees is a good idea and tree planting programmes should continue with greater zeal for their numerous ecosystem services, the present analyses shows that as long as the present emission trends continue, even if we manage to convert the entire land on the planet into a forest, that will not be adequate to completely offset the current rate of build-up of $\mathrm{CO}_{2}$ in the atmosphere and prevent or limit global warming. It has been reported earlier that if all countries in the world would have emitted GHGs into the atmosphere at the same rate as some developed nations did, we would need nine planets to keep the atmospheric concentration of GHGs at the present level HDR [6]. Published data on the global carbon budget shows that build-up of $\mathrm{CO}_{2}$ in the atmosphere is determined more by the amount of global $\mathrm{CO}_{2}$ emission rather than the $\mathrm{CO}_{2}$ sequestration by the planet and therefore, proactively reducing emission is more effective than 
planting more trees in reducing and stabilizing the concentration of $\mathrm{CO}_{2}$ in the atmosphere.

\section{Rate of Increase in the world $\mathrm{CO}_{2}$ Emission and Atmospheric $\mathrm{CO}_{2}$ Concentration between the Period 1950 and 2008:}

Long term data on $\mathrm{CO}_{2}$ emission and atmospheric $\mathrm{CO}_{2}$ concentration were obtained from authentic published sources (http://data.worldbankorg/indicator). Data on terrestrial and ocean $\mathrm{CO}_{2}$ fluxes were taken from the fourth assessment report (AR4) of the Intergovernmental Panel on Climate Change IPCC [2]. Using these data, rate of increase in GHG emission and removal from the atmosphere and increase in the concentration of $\mathrm{CO}_{2}$ in the atmosphere were calculated through regression analysis. The present rate of terrestrial and oceanic removal of $\mathrm{CO}_{2}$ and the rate of build-up of $\mathrm{CO}_{2}$ concentration in the atmosphere were used to estimate the area of land and ocean that is required to fully offset the rise of $\mathrm{CO}_{2}$ in the atmosphere. Linear regression analysis shows that the annual rate of increase in $\mathrm{CO}_{2}$ emission between 1950 and 2008 was $411.30 \mathrm{Mt} \mathrm{CO}_{2}$ per year $\left(\mathrm{R}^{2}=0.98\right)$ and the atmospheric $\mathrm{CO}^{2}$ concentration increased at the rate of $1.30 \mathrm{ppm}$ per year which is equivalent to $10151.06 \mathrm{Mt} \mathrm{CO}_{2}$ per year $\left(\mathrm{R}^{2}=0.97\right)$. Between 1950 and 2008, $\mathrm{CO}_{2}$ emission (including fossil fuel combustion and land use changes) increased from $9450 \mathrm{Mt}$ to $34939 \mathrm{Mt}$. During the same period, atmospheric $\mathrm{CO}_{2}$ concentration increased from 311 ppm to 386 ppm (Figure 1).

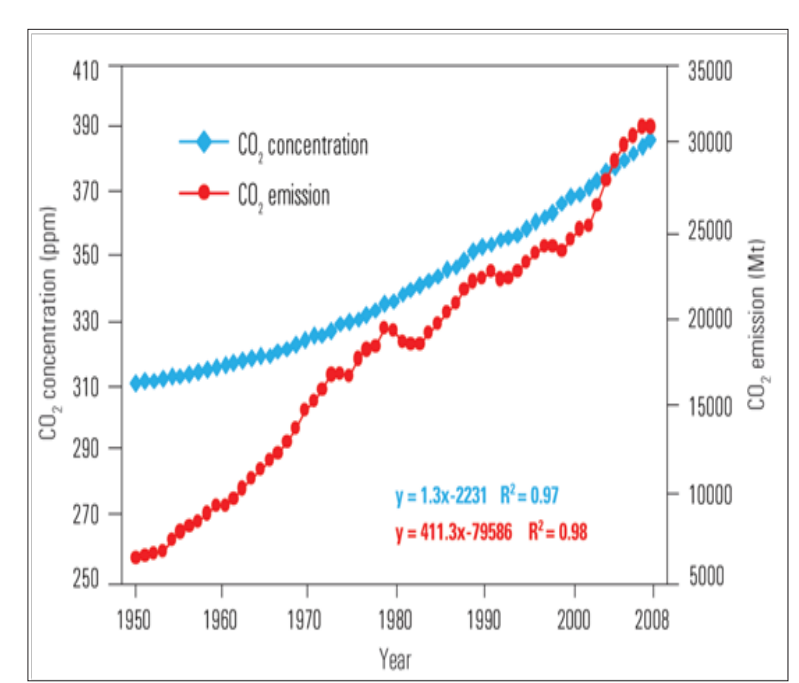

Figure 1: Rate of increase in the world $\mathrm{CO}_{2}$ emission and atmospheric $\mathrm{CO}_{2}$ concentration between the period 1950 and 2008 (Calculated based on the data from Carbon dioxide information analysis center (CDIAC).

The increase in $\mathrm{CO}_{2}$ emission was $270 \%$ while atmospheric $\mathrm{CO}_{2}$ concentration increased only to the tune of $24 \%$. Despite the huge increase in $\mathrm{CO}_{2}$ emission, the atmospheric $\mathrm{CO}_{2}$ did not increase to the same extent and this indicates that the amount of $\mathrm{CO}_{2}$ sequestered by the planet must have increased at a rate greater than the rate at which $\mathrm{CO}_{2}$ increased in the atmosphere between 1950 and 2008. Terrestrial removal of $\mathrm{CO}_{2}$ during 2000-2005 was 0.9 Gt C yr-1 IPCC [2] and this is equal to $3303.0 \mathrm{Mt} \mathrm{CO}_{2}$ per year. Total vegetation area on earth surface is about $15000 \mathrm{M}$ ha [7]. From this it is calculated that the terrestrial carbon fixation rate comes to $220 \mathrm{Kg} \mathrm{CO}_{2}$ per hectare per year. At this rate, we need an additional land area of around $46141.0 \mathrm{M}$ ha for planting trees so as to fully offset the current rate of increase in atmospheric $\mathrm{CO}_{2}$ concentration (which is roughly $1.30 \mathrm{ppm} \mathrm{yr}^{-1}$, averaged for the period 1950-2008, Figure 2). This is equal to the terrestrial vegetation area of three planets.

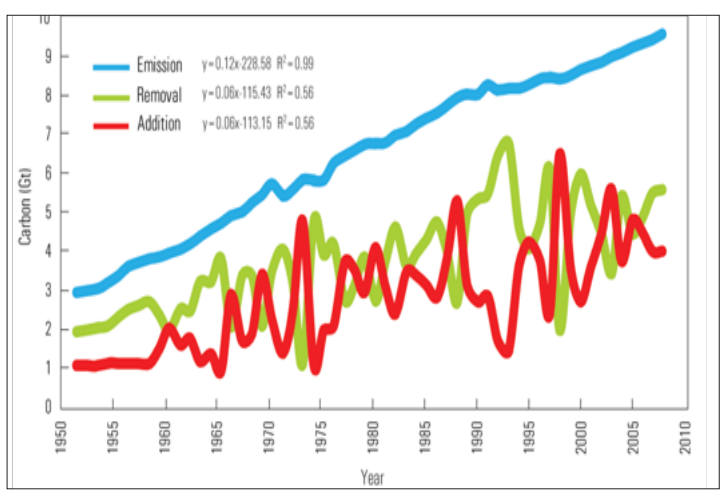

Figure 2: Global carbon balance sheet between 1950 and 2008.

From the emission and atmospheric $\mathrm{CO}_{2}$ concentration data, I calculated the amount of $\mathrm{CO}_{2}$ sequestered as the difference between the former two. The rate of $\mathrm{CO} 2$ emission (including fossil Over the years, concentration of $\mathrm{CO}_{2}$ in the atmosphere has been increasing at an increasing rate. For example, atmospheric $\mathrm{CO}_{2}$ concentration had been increasing at the rate of 2.07 ppm per year between 2000 and 2008 as against 1.30 ppm per year between 1950-2008. Therefore, Afforestation programmes will be even inadequate to offset the build-up of $\mathrm{CO}_{2}$ in the atmosphere today than in the past. We would require a terrestrial vegetation area equivalent to 4.9 planets and a combined area of land and ocean equivalent to 1.6 planets to fully offset the recent rate of increase in atmospheric $\mathrm{CO}_{2}$ concentration. What are the policy implications of this finding in the Indian and global contexts? Renewed efforts to green more land area is one of the major national action plans to mitigate global warming. The annual rate of sequestration of $\mathrm{CO}_{2}$ by Indian forest cover is calculated as 1.94 tons per hectare per year [8]. At this rate, the presently existing total forest and tree cover in the country (76.87 M ha) can sequester $138.15 \mathrm{Mt}$ of $\mathrm{CO}_{2}$ every year.

The total fossil fuel emission from India was $1494.88 \mathrm{Mt} \mathrm{CO}_{2}$ in 2008. To offset this amount of $\mathrm{CO}_{2}$ emission, India should have a forest area of $770.55 \mathrm{M}$ ha and all of that should fix carbon at the same efficiency of 1.94 tons per hectare per year. This additional area is equivalent to 2.3 times the geographical area of the country. In other words, going by the present emission and sequestration rates, the world will not sequester what it emits nor will India sequester what it emits. At the present rate of anthropogenic $\mathrm{CO}_{2}$ emission, our planet will not be able to sequester enough $\mathrm{CO}_{2}$ through the natural process of photosynthesis to prevent further rise in its concentration in the atmosphere, even if we manage to plant trees in every bit of land on the planet and they all fix carbon with the same efficiency. Indian scenario is also not any different; planting trees alone will not take care of our rising emissions. Once 
Mahatma Gandhi reflected on how many planets might be needed to sequester the total emission if India were to follow Britain's pattern of industrialization. Carbon capture and storage (CCS) [9], which amounts to physically trapping $\mathrm{CO}_{2}$ at its source and storing it in large underground geological formations is perhaps the only way we can continue to emit $\mathrm{CO}_{2}$ at the present levels and yet stabilize its atmospheric concentration at some specified level, but this technology is yet to be fully harnessed. While planting trees is not only option for mitigation of climate change but reducing or even stabilizing the concentration of $\mathrm{CO}_{2}$ in the atmosphere at the present level cannot be achieved, unless there are deliberate efforts in reducing the amount of anthropogenic $\mathrm{CO}_{2}$ emission into the atmosphere IPCC [2].

\section{Conclusion}

It is clearly shown that the world is emitting much more $\mathrm{CO}_{2}$ than it can sequester and hence, in equilibrium is on the rise. The result is that $\mathrm{CO}_{2}$ concentration in the atmosphere is increasing at an alarming rate. Planting trees is not only the option to bring this equilibrium back, unless there are deliberate efforts in reducing the amount of anthropogenic $\mathrm{CO}_{2}$ emission into the atmosphere. Emissions and land use changes) from 1950-2008 was 0.12 Gt C yr ${ }^{-1}$. The rate of removal of $\mathrm{CO}_{2}$ from the atmosphere (including land and ocean sinks of $\mathrm{CO}_{2}$ ) and the rate of addition of $\mathrm{CO}_{2}$ to the atmosphere were identical $\left(0.06 \mathrm{Gt} \mathrm{C} \mathrm{yr}^{-1}\right)$ (Figure 1$)$. The rate of emission was much greater than the rate of removal and the difference was 0.06 Gt $\mathrm{C} \mathrm{yr}^{-1}$. This indicates that even if we take the sequestration capacity of the land and ocean together, we will still require one more additional planet to remove the current rate of $\mathrm{CO}_{2}$ emission to maintain equilibrium between the present emission and removal and thus keep the atmospheric $\mathrm{CO}_{2}$ concentration stabilized at the present level.

\section{References}

1. IPCC (2014) Climate Change 2014: Synthesis Report. Contribution of Working Groups I, II and III to the Fifth Assessment Report of the Intergovernmental Panel on Climate Change. Core Writing Team, RK Pachauri and LA Meyer (Eds.). IPCC, Geneva, Switzerland, p. 151.

2. (2007) IPCC, Fourth Assessment Report (AR4), Climate Change 2007, the Physical Science Basis. Contribution of Working Group I to the Fourth Assessment Report of the Intergovernmental Panel on Climate Change. Cambridge University Press, Cambridge, United Kingdom and New York, NY, USA.

3. Galford GL, Melillo JM, Kicklighter DW, Cronin TW, Cerri EPC, et al. ( 2010) Greenhouse gas emissions from alternative futures of deforestation and agricultural management in the southern Amazon. Proceedings of the National Academy of Science. 107(46): 19649-19654.

4. Gillian LG, Jerry MM, David WK, Timothy WC, Carlos EPC, et al. (2010) Greenhouse gas emissions from alternative futures of deforestation and gricultural management in the southern Amazon. Proceedings of National Academy of Science 107(46): 34-42.

5. Daniel N, Britaldo SS, Frank M, André L, Paulo M, et al. (2009) The end of deforestation in the Brazilian Amazon. Science 326(5958): 1350-1351.

6. (2007) Human Development Report 2007/08 Fighting climate change: Human solidarity in a divided world. By United Nations Development Programme (UNDP), 1 UN Plaza, New York, USA.

7. Dixon RK, Solomon AM, Brown S, Houghton RA, Trexier MC, et al. (1994) Carbon Pools and Flux of Global Forest Ecosystems. Science 263(5144): 185-190.

8. Jagadish K, Rajiv P, Dadhwal VK (2009) India's Forest and Tree Cover: Contribution as a Carbon Sink. Technical paper by Indian Council of Forestry Research and Education.

9. Carrington D (2010) Amazon deforestation in dramatic decline, official figures show. Guardian Newspaper Limited, United Kingdom.

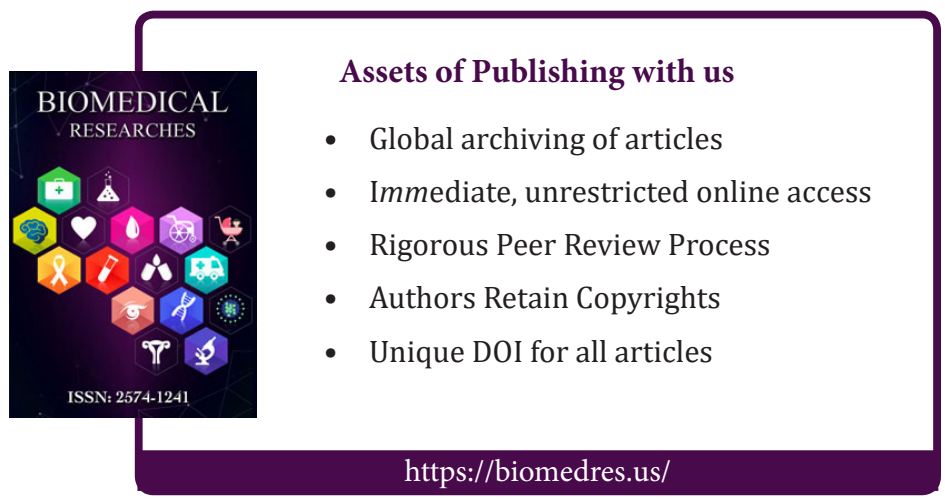

